\title{
Validation of a two-layer depth-averaged model by comparison with an experimental dilute stratified pyroclastic density current
}

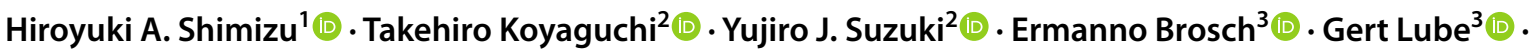 \\ Matteo Cerminara ${ }^{4}$ iD
}

Received: 30 June 2021 / Accepted: 13 September 2021 / Published online: 20 October 2021

(c) The Author(s) 2021

\begin{abstract}
Numerical results of a two-layer depth-averaged model of pyroclastic density currents (PDCs) were compared with an experimental PDC generated at the international eruption simulator facility (the Pyroclastic flow Eruption Large-scale Experiment (PELE)) to establish a minimal dynamical model of PDCs with stratification of particle concentrations. In the present two-layer model, the stratification in PDCs is modeled as a voluminous suspended-load layer with low particle volume fractions $\left(\lesssim 10^{-3}\right)$ and a thin basal bed-load layer with higher particle volume fractions $\left(\sim 10^{-2}\right)$ on the basis of the source condition in the experiment. Numerical results for the suspended load quantitatively reproduce the time evolutions of the front position and flow thickness in the experimental PDC. The numerical results of the bed-load and deposit thicknesses depend on an assumed value of settling speed at the bottom of the bed load $\left(W_{\mathrm{sH}}\right)$. We show that the thicknesses of bed load and deposit in the simulations agree well with the experimental data, when $W_{\mathrm{sH}}$ is set to about $1.25 \times 10^{-2} \mathrm{~m} / \mathrm{s}$. This value of the settling speed is two orders of magnitude smaller than that predicted by a hindered-settling model. The small value of $W_{\mathrm{sH}}$ is considered to result from decreasing in the effective deposition speed due to the erosion process accompanied by saltating/rolling of particles at the bottom of the bed load.
\end{abstract}

Keywords Pyroclastic density current · Two-layer model $\cdot$ Experimental validation $\cdot$ Pyroclastic surge $\cdot$ Bed load · Sedimentation process

\section{Introduction}

Pyroclastic density currents (PDCs) are a frequent and hazardous process during volcanic eruptions. They occur when a hot mixture of volcanic particles and gas is ejected

Editorial responsibility: G.A. Valentine

This paper constitutes part of a topical collection:

Pyroclastic current models: benchmarking and validation

Hiroyuki A. Shimizu

s-hiro@bosai.go.jp

1 National Research Institute for Earth Science and Disaster Resilience, 3-1 Tennodai, Tsukuba, Ibaraki 305-0006, Japan

2 Earthquake Research Institute, The University of Tokyo, 1-1-1 Yayoi, Bunkyo-ku, Tokyo 113-0032, Japan

3 Volcanic Risk Solutions, Massey University, Private Bag 11 222, Palmerston North, New Zealand

4 Istituto Nazionale di Geofisica e Vulcanologia, Sezione di Pisa, Via della Faggiola 32, 56126 Pisa, Italy from the vent, but fails to become buoyant and instead propagates outwards as a ground-hugging gravity current (see the reviews by Branney and Kokelaar (2002), Sulpizio et al. (2014), and Lube et al. (2020)). The flow dynamics of PDCs depends on various factors: eruption conditions such as magma discharge rate (e.g., Bursik and Woods 1996; Dufek and Bergantz 2007; Shimizu et al. 2019; Roche et al. 2021); physical processes of PDCs such as ambient air entrainment, particle sedimentation, and basal friction (e.g., Roche et al. 2008; Andrews and Manga 2012; Lube et al. 2019); and topography (e.g., Esposti Ongaro et al. 2008; Andrews and Manga 2011; Kelfoun 2017). Because of the interplay between these different factors, the fluid dynamical features of PDCs are highly variable and form a wide range of deposit characteristics (e.g., Fisher and Schmincke 1984; Cas and Wright 1987; Branney and Kokelaar 2002).

One major reason behind the wide range of the dynamics of PDCs arises due to strong vertical stratification of the currents with respect to particle concentration (Valentine 1987; 
Branney and Kokelaar 2002; Burgisser and Bergantz 2002; Breard et al. 2016). PDCs are composed mainly of an upper voluminous dilute turbulent suspension region with low particle volume fractions ( $\lesssim 10^{-3}$; referred to as a "suspended load") and a thinner lower region with higher particle volume fractions $\left(\sim 10^{-2}-0.5\right)$. As the particle volume fractions change, the controlling factors of the flow dynamics also change. The flow dynamics of the upper region is controlled mainly by the settling of particles in the current, entrainment of ambient air into the current, thermal expansion of the entrained air, and resistance of ambient air at the flow front (e.g., Sparks et al. 1993; Andrews and Manga 2012; Benage et al. 2016). On the other hand, the flow dynamics of the lower region is controlled mainly by gas-particle interaction, particle-particle collision, frictional interaction between the current and the ground, and deposition/erosion processes at the base (e.g., Roche et al. 2008; Girolami et al. 2010; Lube et al. 2019; Brosch and Lube 2020). The behavior of the whole stratified current is determined by the dynamics of both the upper and lower regions and the interactions between them (i.e., transfers of mass, momentum, and energy from one to the other). The effects of these physical processes on the flow dynamics depend on the source conditions and topography. In particular, the lower region has various characteristics depending on the source conditions (for instance, the particle concentration at the source; e.g., Lube et al. 2015; Breard et al. 2018; Valentine 2020); the lower region behaves as a dense gas-pore pressure-modified (i.e., fluidized) granular flow with very high particle volume fractions $(\sim 0.4$; referred to as a "dense underflow"; e.g., Breard et al. 2016; Roche et al. 2016; Lube et al. 2019) or as a flow of saltating/rolling particles with relatively low particle volume fractions $\left(\sim 10^{-2}\right.$; referred to as a "bed load"; e.g., Valentine 1987; Dufek and Bergantz 2007; Brosch and Lube 2020).

Numerical two-layer depth-averaged models have been developed as a minimal dynamical model to describe global features of stratified PDCs (e.g., Doyle et al. 2008; Kelfoun 2017; Shimizu et al. 2019). In the two-layer models, the continuous stratification of particle concentration and density in PDCs is modeled as upper and lower depth-averaged layers on the basis of the idea that the upper- and lower-region flows in stratified PDCs are controlled by different physical processes. In upper layers, the effects of particle settling, air entrainment, thermal expansion, and frontal air resistance on flow dynamics are mainly taken into account on the basis of experiments of particle-water dilute turbulent suspension flows (e.g., Parker et al. 1987; Bonnecaze et al. 1993; Sparks et al. 1993). In lower layers, the effects of basal friction and deposition on flow dynamics are mainly considered on the basis of experiments of particle-air dense fluidized granular flows (e.g., Girolami et al. 2008, 2010; Roche et al. 2008). The two layers are coupled through mass and momentum exchanges such as inter-layer particle transfer. Although the concept of a two-layer model is useful for systematically assessing the effects of the various physical processes on the flow dynamics and resulting deposits of stratified PDCs, the quantitative agreement of its numerical results with experimental observations needs to be tested.

A community-driven effort is currently underway to compare numerical PDC models with experimental data for the purposes of validation (assessing how well a numerical model represents the physical problem) and benchmarking (comparison of different numerical models with one another) (Valentine 2019; Esposti Ongaro et al. 2020). As a part of the effort, a large-scale experiment was conducted at the international eruption simulator facility (the Pyroclastic flow Eruption Large-scale Experiment (PELE); Lube et al. 2015). This experiment involved the controlled gravitational collapse of a heated suspension of natural volcanic particles and air into an instrumented inclined run-out section. The resulting continuously stratified density current simulated a fully dilute, fully turbulent PDC (i.e., a pyroclastic surge) comprising a thick upper suspended-load region and a thin lower bed-load region. The detailed conditions of the experiment and the characteristics of the spatially and temporally evolving flow structure and deposit are described in Brosch and Lube (2020). The benchmark conditions are described in Supplementary Information S1 in Electronic Supplementary Material (ESM) 1.

This paper compares a numerical two-layer PDC model (Shimizu et al. 2019) with the experimental data from PELE for the benchmarking and validation in order to establish a minimal dynamical model of stratified PDCs. We assess how well the two-layer model reproduces the experimental stratified PDC to clarify its applicability and limitation. We also discuss the sedimentation process in the experimental bed load.

\section{Method}

We conducted a series of numerical simulations of a twolayer PDC model under the conditions defined in the benchmark. A two-layer PDC flows into run-out sections comprising proximal $6^{\circ}$ inclined and distal horizontal channels at $x=0-9.68 \mathrm{~m}$ and $x>9.68 \mathrm{~m}$, respectively, where $x$ represents the distance in a direction parallel to the basal surface (Fig. 1). We set the source conditions using the experimental data at $x=0$ (Profile 1) and compare the numerical results with the experimental data in the distal areas $(x>0)$ particularly at $x=2.65$ and $7.78 \mathrm{~m}$ (Profiles 2 and 3, respectively). The basic equations of the two-layer PDC model and the source conditions and input parameters in the simulations are shown below.

\section{Basic equations}

The present two-layer model is based on that of Shimizu et al. (2019); the two layers are coupled through mass and 


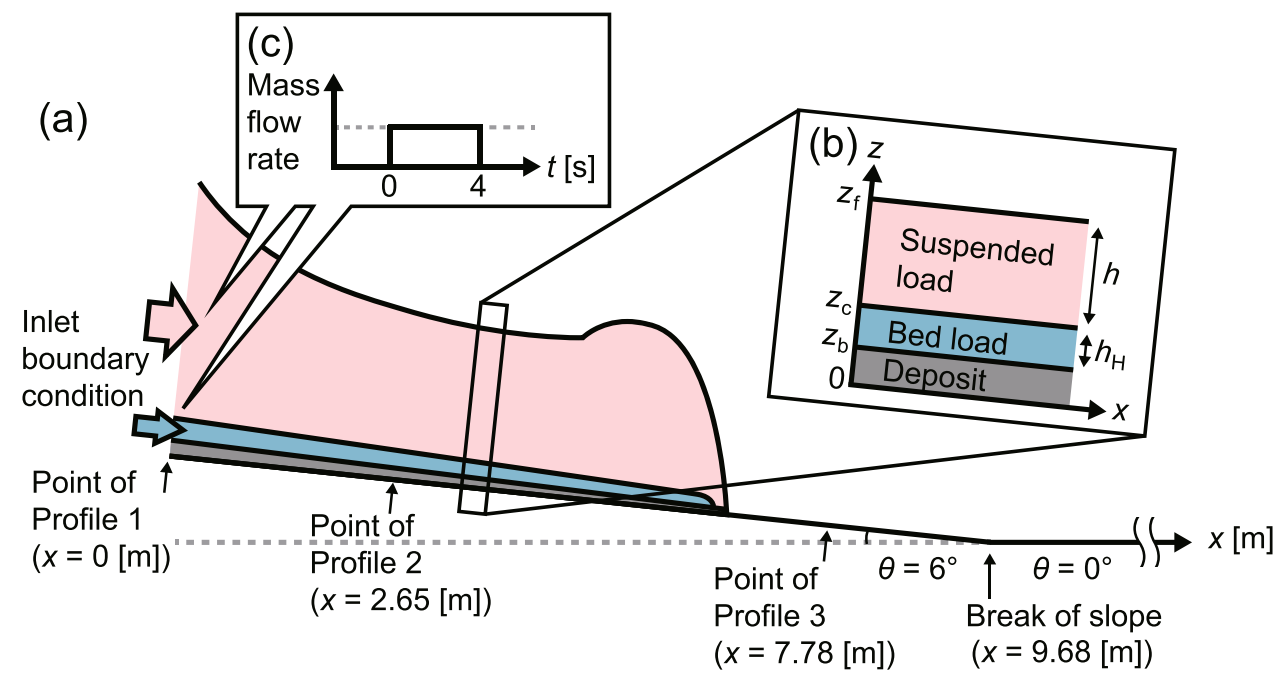

Fig. 1 Schematic illustration of a series of numerical simulations of the two-layer PDC model. a A two-layer PDC is generated from the inlet boundary $(x=0)$ and flows into a proximal inclined channel with length $9.68 \mathrm{~m}$ (slope angle $\theta=6^{\circ}$ ) and into a distal horizontal channel $\left(\theta=0^{\circ}\right)$. $\mathbf{b}$ There are three interfaces, between the upper sus- pended load with thickness $h$ and the ambient air $\left(z=z_{\mathrm{f}}\right)$, between the lower bed load with thickness $h_{\mathrm{H}}$ and the suspended load $\left(z=z_{\mathrm{c}}\right)$, and between the deposit and the bed load $\left(z=z_{\mathrm{b}}\right)$. $\mathbf{c}$ The inlet mass flow rates of the suspended and bed loads are given as constant values for time $t=0-4 \mathrm{~s}$ and as 0 for $t>4 \mathrm{~s}$ momentum exchanges as suspended particles in the upper layer settle into the lower layer, and a deposit progressively aggrades upward from the bottom of the lower (or upper) layer (see Fig. 1b). Shimizu et al. (2019) assumed an axisymmetric PDC spreading radially from the source along the horizontal ground surface, whereas this paper designs a PDC flowing into an inclined one-dimensional channel with a slope angle $\theta$ based on the experimental setting of PELE (see Fig. 1a). The basic equations of the upper and lower layers and the deposit are described below (see Shimizu et al. (2019) for the numerical procedures).

The upper layer is modeled as a suspended load consisting of solid particles, volcanic gas, and entrained ambient air. The basic equations of the suspended load with thickness $h(x, t)$, velocity $u(x, t)$, density $\rho(x, t)$, solid mass fraction $n_{\mathrm{s}}(x, t)$, volcanic gas mass fraction $n_{\mathrm{v}}(x, t)$, air mass fraction $n_{\mathrm{a}}(x, t)$, temperature $T(x, t)$, and specific heat at constant pressure $C_{\mathrm{p}}(x, t)$ are as follows.

Conservation of flow mass:

$\frac{\partial}{\partial t}(\rho h)+\frac{\partial}{\partial x}(\rho u h)=\rho_{\mathrm{a}} E|u|-n_{\mathrm{s}} \rho W_{\mathrm{s}} \cos \theta$

Conservation of entrained air mass:

$\frac{\partial}{\partial t}\left(n_{\mathrm{a}} \rho h\right)+\frac{\partial}{\partial x}\left(n_{\mathrm{a}} \rho u h\right)=\rho_{\mathrm{a}} E|u|$

Conservation of solid particle mass:

$\frac{\partial}{\partial t}\left(n_{\mathrm{s}} \rho h\right)+\frac{\partial}{\partial x}\left(n_{\mathrm{s}} \rho u h\right)=-n_{\mathrm{s}} \rho W_{\mathrm{s}} \cos \theta$
Conservation of flow momentum:

$\frac{\partial}{\partial t}(\rho u h)+\frac{\partial}{\partial x}\left(\rho u^{2} h+\frac{\rho-\rho_{\mathrm{a}}}{2} g h^{2} \cos \theta\right)$

$=\left(\rho-\rho_{\mathrm{a}}\right) g h \sin \theta-\left(\rho-\rho_{\mathrm{a}}\right) g h \cos \theta \frac{\partial z_{\mathrm{c}}}{\partial x}$

$-n_{\mathrm{s}} \rho u W_{\mathrm{s}} \cos \theta-\rho C_{\mathrm{dc}}\left(u-u_{\mathrm{H}}\right)\left|u-u_{\mathrm{H}}\right|$

Conservation of flow enthalpy:

$\frac{\partial}{\partial t}\left(\rho C_{\mathrm{p}} T h\right)+\frac{\partial}{\partial x}\left(\rho C_{\mathrm{p}} T u h\right)$

$=\rho_{\mathrm{a}} E|u|\left(C_{\mathrm{pa}} T_{\mathrm{a}}+\frac{u^{2}}{2}+\frac{g h}{2} \cos \theta\right)$

$-n_{\mathrm{s}} \rho W_{\mathrm{s}} \cos \theta\left(C_{\mathrm{s}} T-\frac{g h}{2} \cos \theta\right)$

Equation of state:

$\frac{1}{\rho}=\frac{n_{\mathrm{s}}}{\rho_{\mathrm{s}}}+\frac{T}{p}\left(n_{\mathrm{a}} R_{\mathrm{a}}+n_{\mathrm{v}} R_{\mathrm{v}}\right)$

Here $t$ is the time, $\rho_{\mathrm{a}}\left(\equiv p /\left(R_{\mathrm{a}} T_{\mathrm{a}}\right)\right)$ is the density of ambient air, $E$ is the entrainment coefficient (see Eq. (A.1) of Shimizu et al. 2019), $W_{s}$ is the settling speed of solid particles at the bottom of the suspended load, $g$ is the gravitational acceleration, $z_{c}$ is the height of the basal contact, $C_{\mathrm{dc}}$ is the basal-drag coefficient of the suspended load, $u_{\mathrm{H}}$ is the lower-layer velocity, $C_{\mathrm{pa}}$ is the specific heat of air at constant pressure, $T_{\mathrm{a}}$ is the temperature of ambient air, $C_{\mathrm{s}}$ is the specific heat of solid particles, $\rho_{\mathrm{s}}$ is the mean density of solid particles, $R_{\mathrm{a}}$ is the gas constant of air, $R_{\mathrm{v}}$ is the gas constant of volcanic gas, and $p$ is the pressure. The mass fractions satisfy the condition of $n_{\mathrm{s}}+n_{\mathrm{v}}+n_{\mathrm{a}}=1$. The specific heat of the suspended load at constant pressure is given by $C_{\mathrm{p}}=n_{\mathrm{s}} C_{\mathrm{s}}+n_{\mathrm{a}} C_{\mathrm{pa}}+n_{\mathrm{v}} C_{\mathrm{pv}}$. The above depth-averaged 
equations provide a good approximation of the dynamics of currents where turbulent mixing is sufficiently intense to maintain vertically uniform concentration (cf. Bonnecaze et al. 1993). To describe realistic suspended-load dynamics, a balance between the buoyancy pressure driving the flow front and the resistance pressure caused by the acceleration of the ambient air at the front (i.e., the front condition):

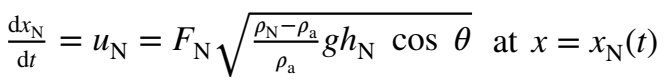

is taken into account, where the subscript $\mathrm{N}$ denotes the front and $F_{\mathrm{N}}$ is the imposed frontal non-dimensional parameter. Equation (7) is applicable to the gravity currents for a wide range of density differences between the current and the ambient fluid (Ungarish 2009; Shimizu et al. 2017).

The lower layer is modeled as a homogeneous bed load (i.e., a homogeneous flow with a higher particle concentration than that of the suspended load) consisting of solid particles and air. The basic equations of the bed load with thickness $h_{\mathrm{H}}(x, t)$ and velocity $u_{\mathrm{H}}(x, t)$ are as follows. Conservation of solid particle mass:

$\frac{\partial h_{\mathrm{H}}}{\partial t}+\frac{\partial}{\partial x}\left(u_{\mathrm{H}} h_{\mathrm{H}}\right)=\frac{n_{\mathrm{s}} \rho}{\phi_{\mathrm{sH}} \rho_{\mathrm{s}}} W_{\mathrm{s}} \cos \theta-\frac{\phi_{\mathrm{sD}}}{\phi_{\mathrm{sD}}-\phi_{\mathrm{sH}}} W_{\mathrm{sH}} \cos \theta$

Conservation of solid particle momentum:

$\frac{\partial}{\partial t}\left(u_{\mathrm{H}} h_{\mathrm{H}}\right)+\frac{\partial}{\partial x}\left(u_{\mathrm{H}}^{2} h_{\mathrm{H}}+\frac{1}{2} \frac{\rho_{\mathrm{H}}-\rho_{\mathrm{a}}}{\rho_{\mathrm{H}}} g h_{\mathrm{H}}^{2} \cos \theta\right)$

$=\frac{\rho_{\mathrm{H}}-\rho_{\mathrm{a}}}{\rho_{\mathrm{H}}} g h_{\mathrm{H}} \sin \theta-\frac{\rho_{\mathrm{H}}-\rho_{\mathrm{a}}}{\rho_{\mathrm{H}}} g h_{\mathrm{H}} \cos \theta \frac{\partial z_{\mathrm{b}}}{\partial x}$

$-\frac{h_{\mathrm{H}}}{\rho_{\mathrm{H}}} \frac{\partial}{\partial x}\left(\left(\rho-\rho_{\mathrm{a}}\right) g h \cos \theta\right)$

$+\frac{n_{\mathrm{s}} \rho}{\phi_{\mathrm{sH}} \rho_{\mathrm{s}}} u W_{\mathrm{s}} \cos \theta-\frac{\phi_{\mathrm{sD}}}{\phi_{\mathrm{sD}}-\phi_{\mathrm{sH}}} u_{\mathrm{H}} W_{\mathrm{sH}} \cos \theta$

$+\frac{\rho}{\rho_{\mathrm{H}}} C_{\mathrm{dc}}\left(u-u_{\mathrm{H}}\right)\left|u-u_{\mathrm{H}}\right|-C_{\mathrm{db}} u_{\mathrm{H}}\left|u_{\mathrm{H}}\right|$

Here the subscript $\mathrm{H}$ denotes the higher particle concentration flow (i.e., the bed load), $\phi_{\mathrm{sH}}$ is the particle volume fraction in the bed load, $\phi_{\mathrm{SD}}$ is the particle volume fraction in the deposit, $W_{\mathrm{sH}}$ is the settling speed of particles at the bottom of the bed load, $z_{\mathrm{b}}$ is the height of the contact between the bed load and the deposit, and $C_{\mathrm{db}}$ is the basal-drag coefficient of the bed load. The bed load is assumed to have a constant bulk density $\rho_{\mathrm{H}}=\phi_{\mathrm{sH}} \rho_{\mathrm{s}}+\left(1-\phi_{\mathrm{sH}}\right) \rho_{\mathrm{gH}}$, where $\rho_{\mathrm{gH}}\left(\equiv p /\left(R_{\mathrm{a}} T_{1}\right)\right)$ is the density of the gas phase in the bed load and $T_{1}$ is the initial temperature of the upper suspended load. To reproduce the experimentally observed fluid dynamical features of the bed load with particle volume fractions less than $\phi_{\mathrm{SD}}\left(\sim 10^{-2}\right)$, we set the particle volume fraction in the lower layer $\left(\phi_{\mathrm{sH}}\right)$ as a model parameter in the present two-layer model.

The deposit progressively aggrades upward from the bottom of the two-layer PDC. The aggradation rate of material in the deposit is expressed by the deposition speed, $D$, as

$\frac{\partial z_{\mathrm{b}}}{\partial t}=D \cos \theta$.
Here, the value of $D$ is calculated from the mass balance at the deposition surface as

$D=\frac{\phi_{\mathrm{s} *}}{\phi_{\mathrm{sD}}-\phi_{\mathrm{s} *}} W_{\mathrm{s} *}$

where $\phi_{\mathrm{s} *}$ is the particle volume fraction in the bed load $\left(\phi_{\mathrm{sH}}\right)$ or that in the suspended load $\left(\phi_{\mathrm{s}} \equiv n_{\mathrm{s}} \rho / \rho_{\mathrm{s}}\right)$ and $W_{\mathrm{s} *}$ is the effective settling speed of particles from the bed load $\left(W_{\mathrm{sH}}\right)$ or that from the suspended load $\left(W_{\mathrm{s}}\right)$. The aggradation for the suspended load occurs when the particle-settling rate from the suspended load is lower than that from the bed load at the position where the bed load is absent (i.e., the two conditions that the right-hand side of Eq. (8) $<0$ and $h_{\mathrm{H}}=0$ are simultaneously satisfied).

\section{Source conditions and input parameters}

\section{Suspended load}

The source of the upper suspended load in the simulations is modeled as a supply of homogeneous mixture at a constant mass flow rate from the inlet boundary $x=0$ (Fig. 1). The values of the inlet boundary conditions for the suspended load (i.e., thickness $h_{1}$, velocity $u_{1}$, solid mass fraction $n_{\mathrm{s} 1}$, volcanic gas mass fraction $n_{\mathrm{v} 1}$, temperature $T_{1}$, and mean solid density $\left.\rho_{\mathrm{s}}\right)$ are obtained from the experimental data at Profile $1(x=0)$ (see Table 1). The values of $h_{1}, u_{1}, n_{\mathrm{s} 1}, n_{\mathrm{v} 1}$, and $T_{1}$ (Table 1 ) are estimated by depth- and time-averaging experimental data of flow velocity, temperature, and particle volume fraction as a function of time $t$ and height $z$ at Profile 1 (see Supplementary Information S1 in ESM 1). As the densities of particles in the experiment depend on their particle sizes (ESM 2), the value of $\rho_{\mathrm{s}}$ is estimated by the mass-weighted average $\left(\sum\left(n_{\mathrm{s}, i} / \rho_{\mathrm{s}, i}\right)\right)^{-1}$, where $n_{\mathrm{s}, i}$ and $\rho_{\mathrm{s}, i}$ are the depth- and time-averaged solid mass fraction and solid density of the $i$-th particle class obtained from the experimental data at Profile 1 (see ESM 2 for details of the estimation). The inlet mass flow rate (per unit length) of the suspended load is given as $\rho_{1} u_{1} h_{1}$ for time $t=0-4 \mathrm{~s}$ and as 0 for $t>4 \mathrm{~s}$ (Fig. 1c), where $\rho_{1}$ represents the density of the suspended load at $x=0$ and is estimated by the equation of state (Eq. (6)). The time interval of $4 \mathrm{~s}$ refers to the duration of high-speed camera footage available to obtain the velocity data at the static observer location in the experiment.

The flow dynamics of the suspended load is dependent on three factors: the imposed frontal non-dimensional parameter $\left(F_{\mathrm{N}}\right)$, the basal-drag coefficient $\left(C_{\mathrm{dc}}\right)$, and the settling speed of solid particles into the bed load (or the deposit) $\left(W_{\mathrm{s}}\right)$. The values of $F_{\mathrm{N}}$ and $C_{\mathrm{dc}}$ (Table 1) are estimated from existing models; $F_{\mathrm{N}}$ is based on the theoretical model for steady-state inviscid gravity currents (Benjamin 1968) and $C_{\mathrm{dc}}$ is estimated on the basis of the empirical formula of Hager (1988) (cf. Hogg and Pritchard 2004). The value of $W_{\mathrm{s}}$ for the polydisperse system (Table 1) is calculated from the mean terminal velocity (see the "Effective values of settling speeds ( $W_{\mathrm{s}}$ and $\left.W_{\mathrm{sH}}\right)$ " section for details). These values of $F_{\mathrm{N}}, C_{\mathrm{dc}}$, 
Table 1 Input parameters and constants for simulation of the two-layer PDC model

\begin{tabular}{|c|c|c|}
\hline Variable & Value [unit] & Meaning \\
\hline$C_{\mathrm{pa}}$ & $1004[\mathrm{~J} /(\mathrm{kg} \mathrm{K})]$ & Specific heat of air at constant pressure \\
\hline$C_{\mathrm{pv}}$ & $1810[\mathrm{~J} /(\mathrm{kg} \mathrm{K})]$ & Specific heat of volcanic gas at constant pressure \\
\hline$C_{\mathrm{s}}$ & $1100[\mathrm{~J} /(\mathrm{kg} \mathrm{K})]$ & Specific heat of solid particles \\
\hline$g$ & $9.81\left[\mathrm{~m} / \mathrm{s}^{2}\right]$ & Gravitational acceleration \\
\hline$p$ & $1.013 \times 10^{5}[\mathrm{~Pa}]$ & Pressure \\
\hline$R_{\mathrm{a}}$ & $287[\mathrm{~J} /(\mathrm{kg} \mathrm{K})]$ & Gas constant of air \\
\hline$R_{\mathrm{v}}$ & $462[\mathrm{~J} /(\mathrm{kg} \mathrm{K})]$ & Gas constant of volcanic gas \\
\hline$T_{\mathrm{a}}$ & $284[\mathrm{~K}]$ & Temperature of ambient air \\
\hline$\rho_{\mathrm{s}}$ & $2177\left[\mathrm{~kg} / \mathrm{m}^{3}\right]$ & Mean density of solid particles \\
\hline$\phi_{\mathrm{sD}}$ & 0.6 & Volume fraction of solid particles in deposit \\
\hline \multicolumn{3}{|c|}{ Suspended load } \\
\hline$C_{\mathrm{dc}}$ & $10^{-3}$ & Basal-drag coefficient of suspended load \\
\hline$F_{\mathrm{N}}$ & $\sqrt{2}$ & Imposed frontal non-dimensional parameter \\
\hline$h_{1}$ & $1.265[\mathrm{~m}]$ & Flow thickness of suspended load at $x=0$ \\
\hline$n_{\mathrm{a} 1}$ & 0.5383 & Mass fraction of air in suspended load at $x=0$ \\
\hline$n_{\mathrm{s} 1}$ & 0.4617 & Mass fraction of solid particles in suspended load at $x=0$ \\
\hline$n_{\mathrm{v} 1}$ & 0 & Mass fraction of volcanic gas in suspended load at $x=0$ \\
\hline$T_{1}$ & $292.29[\mathrm{~K}]$ & $\begin{array}{l}\text { Temperature of suspended load at } x=0 \text { (temperature of particle- } \\
\text { air mixture before gravitational collapse in the experiment is } \\
393 \mathrm{~K} \text { ) }\end{array}$ \\
\hline$u_{1}$ & $4.80[\mathrm{~m} / \mathrm{s}]$ & Flow velocity of suspended load at $x=0$ \\
\hline$W_{\mathrm{s}}$ & $0.75[\mathrm{~m} / \mathrm{s}]$ & Settling speed of solid particles at bottom of suspended load \\
\hline$\phi_{\mathrm{s} 1}$ & $\approx 4.755 \times 10^{-4}$ & Volume fraction of solid particles in suspended load at $x=0$ \\
\hline \multicolumn{3}{|c|}{ Bed load [values for the best-fit results; i.e., Run Best-fit] } \\
\hline$C_{\mathrm{db}}$ & $2.2 \times 10^{-3}$ & Basal-drag coefficient of bed load \\
\hline$h_{\mathrm{H} 1}$ & $0.015[\mathrm{~m}]$ & Flow thickness of bed load at $x=0$ \\
\hline$n_{\mathrm{sH}}$ & $\approx 0.9735$ & Mass fraction of solid particles in bed load \\
\hline$u_{\mathrm{H} 1}$ & $3[\mathrm{~m} / \mathrm{s}]$ & Flow velocity of bed load at $x=0$ \\
\hline$W_{\mathrm{sH}}$ & $1.25 \times 10^{-2}[\mathrm{~m} / \mathrm{s}]$ & Settling speed of solid particles at bottom of bed load \\
\hline$\phi_{\mathrm{sH}}$ & 0.02 & Volume fraction of solid particles in bed load \\
\hline
\end{tabular}

and $W_{\mathrm{s}}$ are assessed by comparison of the numerical results of the suspended load with the experimental data at $x>0$.

\section{Bed load}

In the simulations, a bed load is supplied at the inlet boundary $x=0$ at a constant mass flow rate (Fig. 1). The inlet boundary conditions of the bed load (i.e., thickness $h_{\mathrm{H} 1}$, velocity $u_{\mathrm{H} 1}$, and solid volume fraction $\phi_{\mathrm{sH}}$ ) are obtained from the experimental data (see Table 1 and Supplementary Information S1 in ESM 1). The value of $h_{\mathrm{H} 1}$ (Table 1) is based on the time-series of the bed-load thickness at Profile $1(x=0)$. The value of $u_{\mathrm{H} 1}$ (Table 1 ) is estimated by depth averaging the time-averaged height-dependent fitting function of flow velocity at Profile 1 between heights 0 and $h_{\mathrm{H} 1}$. The value of $\phi_{\mathrm{sH}}$ (Table 1) is based on the observation that the bed load has solid volume fractions of $\sim 10^{-2}$ (Brosch and Lube 2020). The inlet mass flow rate (per unit length) of the bed load is given as $\rho_{\mathrm{H}} u_{\mathrm{H} 1} h_{\mathrm{H} 1}$ for time $t=0-4 \mathrm{~s}$ and as 0 for $t>4$ $\mathrm{s}$ (Fig. 1c). The duration of $t=0-4 \mathrm{~s}$ roughly represents the time interval within which the bed load existed at Profile 1 in the experiment (see Fig. S1a in ESM 1).

The flow dynamics of the bed load is controlled by two major factors: the basal-drag coefficient $\left(C_{\mathrm{db}}\right)$ and the settling speed of particles at the bottom of the bed load $\left(W_{\mathrm{sH}}\right)$. The value of $C_{\mathrm{db}}$ (Table 1) is based on the empirical formula of Hager (1988) (i.e., $C_{\mathrm{db}}=0.025 R e_{\mathrm{H} 1}^{-0.2}$; cf. Hogg and Pritchard 2004), where $R e_{\mathrm{H} 1}\left(\equiv \rho_{\mathrm{H}} u_{\mathrm{H} 1} h_{\mathrm{H} 1} / \eta_{\mathrm{H}}\right)$ represents the Reynolds number of the bed load at $x=0$, and the bulk dynamic viscosity of the bed load $\left(\eta_{\mathrm{H}}\right)$ is set to $10^{-5} \mathrm{~Pa} \mathrm{~s}$. The effective value of $W_{\mathrm{sH}}$ is evaluated below.

\section{Effective values of settling speeds $\left(W_{\mathrm{s}}\right.$ and $\left.W_{\mathrm{sH}}\right)$}

Among the above parameters, the effective values of settling speeds ( $W_{\mathrm{s}}$ and $W_{\mathrm{sH}}$ ) play a key role. Previously, the 
sedimentation process from particle-laden density currents has been explained by a simple settling model based on the terminal velocity $W_{\mathrm{T}}$ (e.g., Bonnecaze et al. 1993; Choux and Druitt 2002; Girolami et al. 2010). We use the mean terminal velocity, $W_{\mathrm{T}}=\sum\left(n_{\mathrm{s}, i} W_{\mathrm{T}, i}\right)$, as a parameter for the polydisperse system (see ESM 2 for details of the estimation). Here the terminal velocity of each $i$-th particle class $\left(W_{\mathrm{T}, i}\right)$ is estimated by Kunii and Levenspiel (1969):

$$
W_{\mathrm{T}, i}=\left\{\begin{array}{cc}
\frac{\left(\rho_{\mathrm{s}, i}-\rho_{\mathrm{g}}\right) g d_{i}^{2}}{18 \eta_{\mathrm{g}}} & \left(R e_{\mathrm{s}, i} \leq 6\right) \\
d_{i}\left(\frac{4\left(\rho_{\mathrm{s}, i}-\rho_{\mathrm{g}}\right)^{2} g^{2}}{225 \eta_{\mathrm{g}} \rho_{\mathrm{g}}}\right)^{1 / 3} & \left(R e_{\mathrm{s}, i}=6-500\right) \\
\left(\frac{3.1\left(\rho_{\mathrm{s}, i}-\rho_{\mathrm{g}}\right) g d_{i}}{\rho_{\mathrm{g}}}\right)^{1 / 2} & \left(R e_{\mathrm{s}, i} \geq 500\right)
\end{array}\right.
$$

where $d_{i}$ is the particle diameter, $\rho_{\mathrm{g}}\left(=1.2 \mathrm{~kg} / \mathrm{m}^{3}\right)$ is the density of the gas phase, $\eta_{\mathrm{g}}\left(=10^{-5} \mathrm{~Pa} \mathrm{~s}\right)$ is the dynamic viscosity of the gas phase, and $R e_{\mathrm{s}, i}\left(\equiv \rho_{\mathrm{g}} d_{i} W_{\mathrm{T}, i} / \eta_{\mathrm{g}}\right)$ is the particle Reynolds number.

Generally, the settling speed of particles in particle-fluid mixture deviates from $W_{\mathrm{T}}$ due to the effects of fine (wellcoupled) particles on the mixture density and viscosity as well as that of counter flow associated with particle settling (Marble 1970). These effects can be taken into account by a formula (Richardson and Zaki 1954) as

$W_{\mathrm{s} *}=\left(1-\phi_{\mathrm{s} *}\right)^{m} W_{\mathrm{T}}$

(referred to as the hindered-settling model), where $m(=2$ $-12)$ is the empirical exponent depending on the particle size. Equation (13) is applicable for a wide range of the particle volume fraction from dilute suspension to fluidized bed (Khan and Richardson 1989; Druitt et al. 2007). It implies that the hindered-settling effects diminish for $\phi_{\mathrm{s} *} \ll 1$ and that the effective value of settling speed in the suspended load $\left(W_{\mathrm{s}}\right)$ is approximated by $W_{\mathrm{T}}$. Consequently, we use $W_{\mathrm{s}}=W_{\mathrm{T}}$ for the suspended load (Table 1), which means that the particle size distribution in the suspended load is assumed to stay constant through time and space. We also use $W_{\mathrm{sH}}=\left(1-\phi_{\mathrm{sH}}\right)^{m} W_{\mathrm{T}}$ (i.e., Eq. (13)) for the bed load in the reference simulation (referred to as "Run Reference").

We consider that care should be taken in the application of Eq. (13) for the bed load, because the settling speed for the bed load is thought to depend strongly on unknown physical processes in the bed load. Equation (13) does not consider some effects that can play a role at the bottom of particle-laden density currents such as erosion of deposits and saltating/rolling of particles. It also ignores the effect of particle cluster, observed in recent experiments (e.g., Lube et al. 2015; Breard et al. 2016; Weit et al. 2018). For these reasons, in simulations other than Run Reference, we set $W_{\mathrm{sH}}$ as a tuning parameter and estimate its value on the basis of fitting the numerical results to the experimental data at $x>0$ (see Table 1 for the value of $W_{\mathrm{sH}}$ in the best fitted simulation (referred to as "Run Best-fit")). We also discuss the sedimentation process in the bed load on the basis of the difference between Runs Reference and Best-fit.

\section{Results}

\section{Suspended load}

The results of the suspended loads in the numerical simulations are almost unaffected by the characteristics of the bed load regardless of $W_{\mathrm{sH}}$, because the bed loads have a negligible effect on the dynamics of the suspended load (e.g., the interfacial drag between the two layers). Here we describe the flow dynamical features of the suspended load in the results reproducing the behavior of the experimental bed load (i.e., Run Best-fit with $W_{\mathrm{sH}}=1.25 \times 10^{-2} \mathrm{~m} / \mathrm{s}$ ).

In the simulation, a suspended load is generated from the inlet boundary $(x=0)$ and flows into the run-out sections $(x>0)$ (see Fig. 2 and Supplementary Movie 1 (ESM 3)). The numerical results successfully reproduce the qualitative features of the suspended load observed in the experiment. They develop a typical gravity current structure comprising a leading thick gravity current "head" and a trailing gravity current "body" (cf. Brosch and Lube 2020). The results also agree well quantitatively with the main components of the experimental data. They reproduce the time evolution of the front position in the experiment (Fig. 3a). The flow thickness in the simulations $(h(x, t))$ is consistent with the time evolution of the flow thickness (particularly the body thickness) at Profiles 2 and $3(x=2.65$ and $7.78 \mathrm{~m}$ ) in the experiment (Fig. $3 \mathrm{~b}$ and c). A brief description of the numerical suspended load is as follows: it has the flow velocity $u \sim 4-5 \mathrm{~m} / \mathrm{s}$, flow density $\rho \sim 1.7-2.3 \mathrm{~kg} / \mathrm{m}^{3}$, and Richardson number $R i \sim 0.1$ -0.4 (i.e., entrainment coefficient $E \sim 0.008-0.04$ ) at $x=0-7.78$ $\mathrm{m}$. Although the thickness of the head in the simulation does not perfectly agree with the experimental data (Fig. $3 \mathrm{~b}$ and c), this difference is acceptably small, given the fact that the frontal shape in the simulation is determined by the mechanical balance of the depth-averaged model (Eq. (7)) and that the other fluid dynamical effects are not considered.

We performed a parametric study for a wide range of input parameters (i.e., $W_{\mathrm{s}}=0.3-3 \mathrm{~m} / \mathrm{s}, F_{\mathrm{N}}=1-\sqrt{2}$, and $C_{\mathrm{dc}}=10^{-4}-10^{-2}$ ) to assess the values of $W_{\mathrm{s}}, F_{\mathrm{N}}$, and $C_{\mathrm{dc}}$ in Table 1 . The results of the parametric study indicate that the dynamical features of the suspended load are insensitive to $C_{\mathrm{dc}}$. On the other hand, they are highly sensitive to $W_{\mathrm{s}}$ and $F_{\mathrm{N}}$. The evolution of the body thickness is primarily affected by the flow density, which in turn depends on $W_{\mathrm{s}}$. The front position strongly depends not only on $W_{\mathrm{s}}$ but also on $F_{\mathrm{N}}$. This is because the time evolution of the flow front, as well as the head and body structure, is controlled primarily by the resistance 
Fig. 2 Representative numerical results of a two-layer PDC at times $t=\mathbf{a} 3.0, \mathbf{b} 4.5$, c 6.0 , and $\mathbf{d} 6.5 \mathrm{~s}$ from the beginning of propagation in Run Best-fit. Thicknesses of the suspended load $(h(x, t)$; red), bed load $\left(h_{\mathrm{H}}(x, t)\right.$; blue), and deposit $\left(z_{\mathrm{b}}(x, t)\right.$; black) are shown
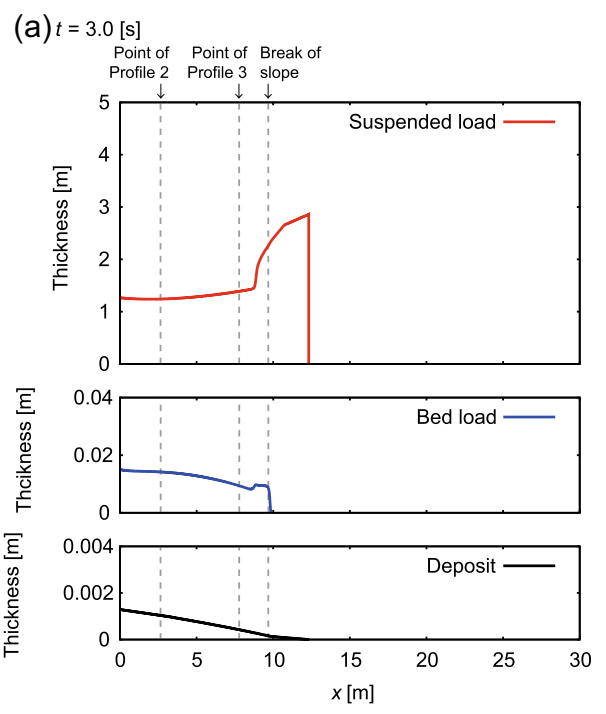

(c) $t=6.0[\mathrm{~s}]$
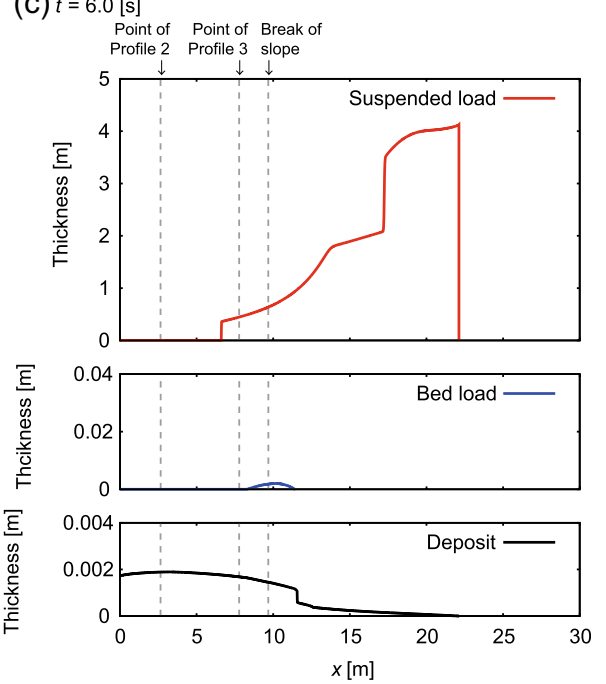

(b) $t=4.5[\mathrm{~s}]$
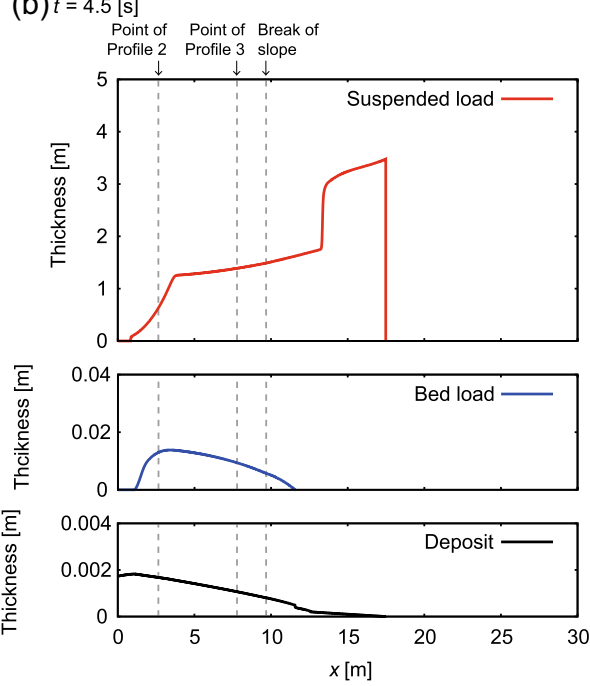

(d) $t=6.5[\mathrm{~s}]$
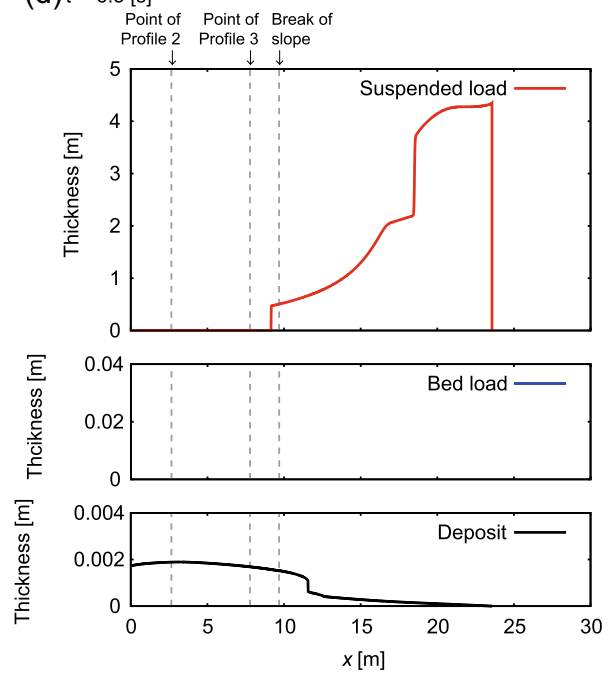

pressure caused by the acceleration of the ambient air at the flow front (i.e., the front condition (Eq. (7)); Shimizu et al. 2017). The above good agreement of the body thickness between the numerical and experimental results (Fig. $3 \mathrm{~b}$ and c) implies that the mass-weighted average of terminal velocities (i.e., $W_{\mathrm{T}}=\sum\left(n_{\mathrm{s}, i} W_{\mathrm{T}, i}\right)$ ) used in the present model can explain the effective value of $W_{\mathrm{s}}$ in the experiment. The agreement for the front position (Fig. 3a) implies that the theoretical model of $F_{\mathrm{N}}$ for steady-state inviscid gravity currents (Benjamin 1968) used in the present model explains the mechanical balance at the flow front in the experiment.

\section{Bed load and deposit}

In the simulations, a bed load is generated from the inlet boundary $(x=0)$ and flows into the run-out sections $(x>0)$ (see Fig. 2 and Supplementary Movie 1 (ESM 3) for the results of Run Best-fit with the values of the input parameters in Table 1). The bed load obtains the mass and momentum of particles settling from the upper suspended load. The front of the bed load stops when its frontal parallel mass flux becomes zero owing to basal deposition (cf. Shimizu et al. 2019). The deposits progressively aggrade upward from the bottom of the bed load in the proximal area and directly from the bottom of the suspended load in the distal area where the bed load is absent (cf. Regime 2a of Shimizu et al. 2019).

When the setting speed at the bottom of the bed load $\left(W_{\mathrm{sH}}\right)$ is set to the value based on the hindered-settling model (Run Reference with $W_{\mathrm{sH}}=5.9 \times 10^{-1} \mathrm{~m} / \mathrm{s}$; i.e., Eq. (13) with $m=12$ ), the numerical results do not reproduce the experimental results for the bed load and deposit. The bed load is hardly observed in the simulation: its runout distance is extremely short $(\sim 0.1 \mathrm{~m}$; see Supplementary Movie 2 (ESM 4)). Furthermore, the numerical result generates an unrealistically thick $(\sim 8 \mathrm{~cm})$ deposit near $x=0$, which was not observed in the experiment. 
Fig. 3 Comparison of the numerical results for the suspended load with the experimental data. Solid black curves represent the numerical results. Circles represent the experimental data. a Front position of the suspended load as a function of time $t\left(x_{\mathrm{N}}(t)\right)$. b and $\mathbf{c}$ Thicknesses of the suspended load at $x=2.65$ and $7.78 \mathrm{~m}$ as a function of time $t(h(x=2.65, t)$ and $h(x=7.78, t))$. In the numerical and experimental results, the thick head passes initially, and the body passes subsequently at $x=2.65$ and $7.78 \mathrm{~m}$. Gray solid lines represent the time-averaged values of the experimental data $(\mathbf{b} h=1.35 \mathrm{~m}(t=0.52$ $-4.5 \mathrm{~s}) ; \mathbf{c} h=1.29 \mathrm{~m}(t=1.9$ $-5.9 \mathrm{~s}))$

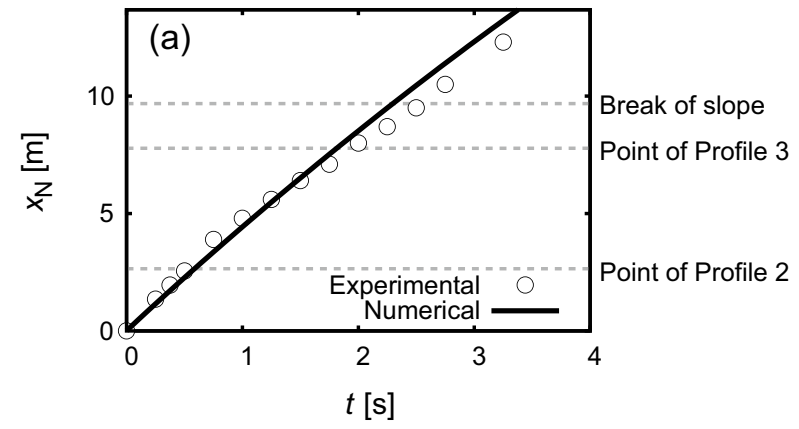

$x=2.65[\mathrm{~m}]($ Point of Profile 2)

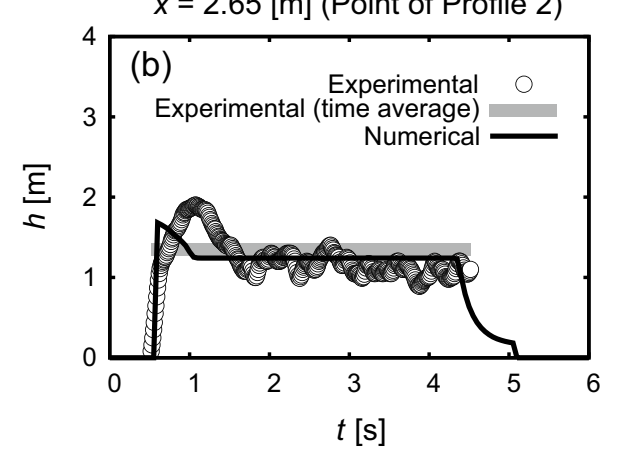

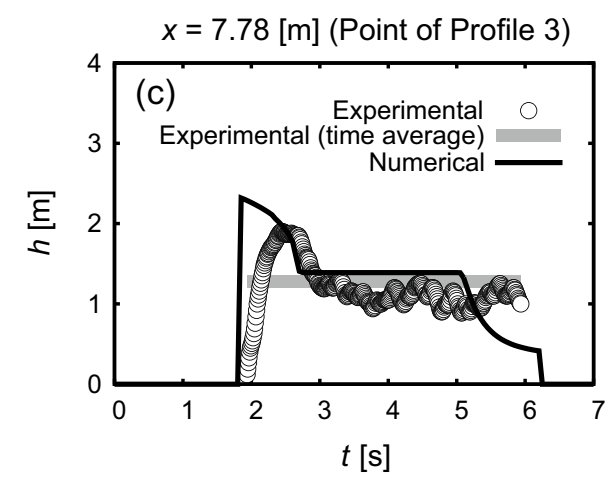

The agreement between the numerical and experimental results for the bed load and deposit is improved when $W_{\mathrm{sH}}$ is set to $1.25 \times 10^{-2} \mathrm{~m} / \mathrm{s}$ (Table 1; i.e., Run Best-fit). The numerical results reproduce the time-averaged data of the bed-load thickness at Profiles 2 and $3(x=2.65$ and $7.78 \mathrm{~m})$ in the experiment (Fig. $4 \mathrm{a}$ and b). The deposit mass in the simulation explains the spatial average of the final deposit mass per unit area in the area of Profiles 1-3 in the experiment (Fig. 4c); the unrealistically thick deposit near $x=0$ observed in Run Reference disappears. The fact that the numerical results do not reproduce the exponential decay of the experimental deposit mass with distance (see Fig. 4c) is due to that the deposition speed at the bottom of the bed load becomes constant value for given $W_{\mathrm{sH}}$ and $\phi_{\mathrm{sH}}$ in the present model (see Eqs. (10) and (11)).

The results of the numerical simulations for a wide range of $W_{\mathrm{sH}}$ indicate that, as $W_{\mathrm{sH}}$ increases, the slope of the bed-load thickness (i.e., $\partial h_{\mathrm{H}} / \partial x$ ) decreases, and the deposit mass (per unit area) derived from the bed load increases. These results allow us to estimate the possible range of $W_{\mathrm{sH}}$ from the following experimental observations: (1) the bed-load thickness has almost the same value (i.e., 0.005-0.02 m) at Profiles 1-3 (see Fig. 4 a and b; see Fig. S1a in ESM 1), and (2) the deposit derived from the bed load has a mass of $0.8-5 \mathrm{~kg} / \mathrm{m}^{2}$ at Profiles 1-3 (see Fig. 4c). The estimated value of $W_{\mathrm{sH}}$ depends on the uncertainties of other parameters for the bed load such as $h_{\mathrm{H} 1}$, $u_{\mathrm{H} 1}, \phi_{\mathrm{sH}}$, and $C_{\mathrm{db}}$; these uncertainties are caused mainly by depth- and/or time-averaging procedures for the experimental data at Profile 1 (see Supplementary Information S1 in ESM 1 for details of the estimations of these uncertainties). To assess the effects of these uncertainties, we performed sensitivity analyses for $h_{\mathrm{H} 1}=0.005-0.02 \mathrm{~m}, u_{\mathrm{H} 1}=2.36-3.27$ $\mathrm{m} / \mathrm{s}, \phi_{\mathrm{sH}}=0.01-0.05$, and $C_{\mathrm{db}}=1.0 \times 10^{-3}-4.0 \times 10^{-3}$.

The results of the sensitivity analyses indicate that the bedload thickness (i.e., Fig. $4 \mathrm{a}$ and b) is dependent on the above four parameters as well as $W_{\mathrm{sH}}$. When the uncertainties of $h_{\mathrm{H} 1}, u_{\mathrm{H} 1}$, $\phi_{\mathrm{sH}}$, and $C_{\mathrm{db}}$ are taken into account, the results of our model with $W_{\mathrm{sH}}=0-5.4 \times 10^{-2} \mathrm{~m} / \mathrm{s}$ agree with the experimental data of the bed-load thickness at Profiles 1-3 (i.e., 0.005-0.02 m). On the other hand, our two-layer model indicates that the final deposit mass derived from the bed load is given by $\phi_{\mathrm{sD}} \rho_{\mathrm{s}} \frac{\phi_{\mathrm{sH}}}{\phi_{\mathrm{sD}}-\phi_{\mathrm{sH}}} W_{\mathrm{sH}} \Delta t \cos \theta$ (see Eqs. (10) and (11)), where $\Delta t$ $(=3.30-3.77 \mathrm{~s})$ is the time interval within which the bed load exists at $x=0-7.78 \mathrm{~m}$ (see Figs. $4 \mathrm{a}$, b and S1a). In other words, the final deposit mass from the bed load at specific points depends on $\phi_{\mathrm{sH}}$ and $W_{\mathrm{sH}}$ for given $\Delta t$. Accordingly, when the uncertainty of $\phi_{\mathrm{sH}}$ is taken into account, the experimental deposit mass (i.e., $0.8-5 \mathrm{~kg} / \mathrm{m}^{2}$ at $x=0-7.78 \mathrm{~m}$ ) is explained by $W_{\mathrm{sH}}=2.1 \times 10^{-3}-6.0 \times 10^{-2} \mathrm{~m} / \mathrm{s}$. Unifying these two constrains from the bed-load thickness and the deposit mass, we conclude that the range of $W_{\mathrm{sH}}$ best explaining the experimental data of both the bed-load thickness and deposit mass is $2.1 \times 10^{-3}-5.4 \times 10^{-2} \mathrm{~m} / \mathrm{s}$. The circle with error bars in Fig. 5 shows the possible range of $W_{\mathrm{sH}}$ (normalized by the mean terminal velocity $W_{\mathrm{T}}$, i.e., $W_{\mathrm{sH}} / W_{\mathrm{T}}=2.8 \times 10^{-3}-7.2 \times 10^{-2}$ ) estimated from the experimental observation for $\phi_{\mathrm{sH}}=0.01-0.05$. The estimated range of $W_{\mathrm{sH}} / W_{\mathrm{T}}$ is two orders of magnitude smaller than that predicted by the hindered-settling model (the gray region in Fig. 5); Eq. (13) predicts $W_{\mathrm{sH}} / W_{\mathrm{T}}=5.4 \times 10^{-1}$ $-9.8 \times 10^{-1}$ for $\phi_{\mathrm{sH}}=0.01-0.05$. 
Fig. 4 Comparison of the numerical results for the bed load and deposit with the experimental data. Solid curves represent the numerical results. Circles represent the experimental data. Typical error bars represent those of the numerical results for the estimations of the possible range of $W_{\mathrm{sH}}$. $\mathbf{a}$ and $\mathbf{b}$ Thicknesses of the bed load at $x=2.65$ and $7.78 \mathrm{~m}$ as a function of time $t\left(h_{\mathrm{H}}(x=2.65, t)\right.$ and $\left.h_{\mathrm{H}}(x=7.78, t)\right)$. Gray solid lines represent the time-averaged values of the experimental data $\left(\mathbf{a} h_{\mathrm{H}}=1.46 \times 10^{-2}\right.$ $\mathrm{m}(t=0.96-4.5 \mathrm{~s}) ; \mathbf{b}$ $h_{\mathrm{H}}=7.94 \times 10^{-3} \mathrm{~m}(t=2.6-5.9$ s)). c Final deposit mass per unit area as a function of distance $x$ $\left(\phi_{\mathrm{sD}} \rho_{\mathrm{s}} z_{\mathrm{b}}(x, t=\infty)\right)$
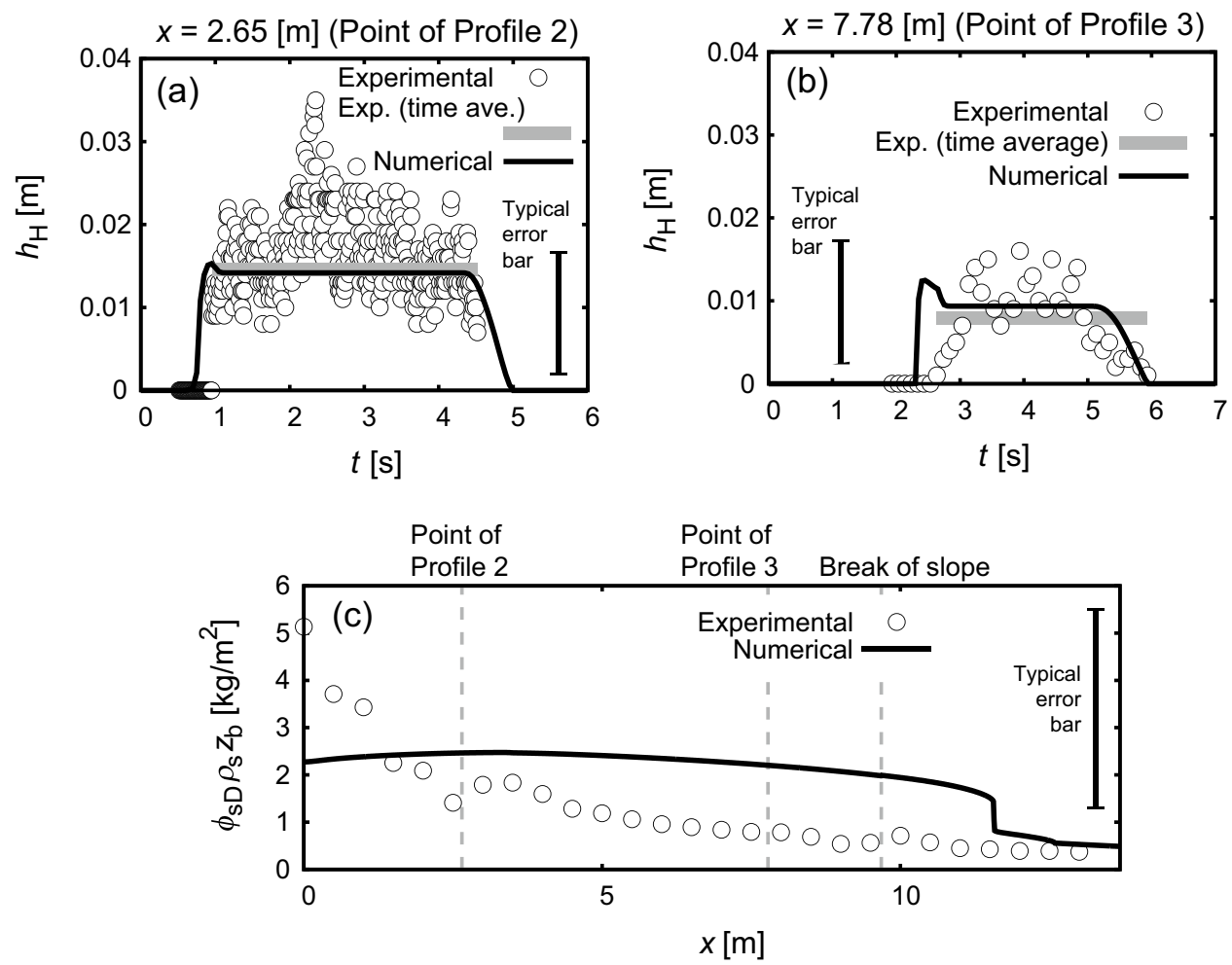

The present two-layer model includes a number of parameters, whereas $W_{\mathrm{sH}}$ is the only tuning parameter in the above comparison with the PELE experiment. The deviation in Fig. 5 may result from the propagation of the uncertainties of unknown factors. To eliminate this possibility, we validate our numerical model for the lower layer using a supplementary comparison with an experiment of initially fluidized granular flows, where the hindered settling successfully explains its sedimentation process (Girolami et al. 2010). The results in Supplementary Information S2 (in ESM 1) show that the numerical results of a basal-layer model with the hinderedsettling model (i.e., Eq. (13)) agree well with the experimental data reported by Girolami et al. (2008). Accordingly, the deviation observed in Fig. 5 suggests that a certain mechanism other than hindered settling plays a role in the sedimentation process in the experimental bed load.

There are at least two physical processes related to $W_{\mathrm{sH}}$ that are not considered in Eq. (13): particle cluster and erosion. According to experimental studies, particle clusters develop in the mixture with intermediate particle volume fractions $\left(10^{-2}-10^{-1}\right)$, which can substantially increase the effective values of $W_{\mathrm{sH}}$ (Weit et al. 2018; Brosch and Lube 2020). In the experiments of particle-laden density currents, on the other hand, the deposition speed at the base of the currents is affected by a complex combination of deposition and erosion processes, and the erosion process can significantly decrease the deposition speed, $D$ (Andrews and Manga 2012; Brosch and Lube 2020). As shown in Eq. (11), $W_{\mathrm{sH}}$ is directly 
related to the deposition speed $D$. The decrease in $D$ leads to a small effective value of $W_{\mathrm{sH}}$. In the present case, the results in Fig. 5 (i.e., the fact that $W_{\mathrm{sH}}$ estimated from the experiment is two orders of magnitude smaller than the value based on the hindered-settling model) indicate that the erosion effect is greater than the particle-cluster effect.

In the experiment, the deposition speed varied temporally and spatially, being accompanied by saltating/rolling particles and shifting/breaking sandwaves in the bed load (Brosch and Lube 2020). On the other hand, the present model assumes that $\phi_{\mathrm{sH}}$ and $W_{\mathrm{sH}}$ (hence $D$ ) have constant values regardless of the time and the distance from the source. The experimental results also suggest that the complex particletransport due to the strong shear in the transient region between the suspended and bed loads significantly influences the effective value of $W_{\mathrm{sH}}$ (see Brosch and Lube 2020 for details), which cannot be accounted for by the present two-layer model. The disagreement between the numerical and experimental results for the profile of the deposit mass (Fig. 4c) is considered to result from those spatiotemporal variations in $\phi_{\mathrm{sH}}$ and $W_{\mathrm{sH}}$ (hence $D$ ) due to the complex combination of deposition and erosion processes.

In this paper, we have focused on the dynamics of stratified PDCs with a bed load generated at the base. As mentioned in the "Introduction" section, the lower region in a stratified PDC flows as either bed load $\left(\phi_{\mathrm{SH}} \sim 10^{-2}\right)$ or dense underflow ( $\left.\phi_{\mathrm{sH}} \sim 0.4\right)$, and this difference in the lower region changes the flow and sedimentation of PDCs (e.g., Lube et al. 2015, 2020; Breard et al. 2018). Our two-layer model can predict the behavior of stratified PDCs only when the inlet source conditions of the lower region (i.e., $h_{\mathrm{H} 1}$, $u_{\mathrm{H} 1}$, and $\left.\phi_{\mathrm{sH}}\right)$ as well as the effective vertical mass fluxes of particles (i.e., $W_{\mathrm{s}}$ and $W_{\mathrm{sH}}$ ) and the effective basal friction (i.e., $C_{\mathrm{db}}$ ) are provided. Future works will attempt to develop additional models to determine these parameters for cases where dense underflow or bed load develops at the source (e.g., Breard et al. 2018; Lube et al. 2019; Valentine 2020).

\section{Summary}

Numerical results of a two-layer depth-averaged model of PDCs with stratification of particle concentrations were compared with an experimental dilute stratified PDC generated at PELE. In the numerical simulations of the present two-layer model, the stratification in PDCs is modeled as a voluminous suspendedload layer with low particle volume fractions $\left(\lesssim 10^{-3}\right)$ and a thin lower bed-load layer with higher particle volume fractions $\left(\sim 10^{-2}\right)$ on the basis of the experimental source conditions. By fitting the numerical results to the experimental data for the bed load and deposit, the settling speed at the bottom of the bed load $\left(W_{\mathrm{sH}}\right)$ has been estimated to be two orders of magnitude smaller than that predicted by the hindered-settling model. The small effective value of $W_{\mathrm{sH}}$ is considered to result from the erosion process accompanied by saltating/rolling of particles at the deposition surface. Further understanding of PDC dynamics based on the two-layer model would require similar comparisons under various source conditions (e.g., those where a dense underflow develops).

\section{Appendix}

We provide the list of the mathematical symbols used in this paper (Table 2).

Table 2 List of symbols

\begin{tabular}{|c|c|}
\hline Symbol & Definition \\
\hline$C_{\mathrm{d}}$ & Basal-drag coefficient \\
\hline$C_{\mathrm{p}}$ & Specific heat (of suspended load) at constant pressure, $\mathrm{J} /(\mathrm{kg} \mathrm{K})$ \\
\hline$C_{\mathrm{s}}$ & Specific heat of solid particle, $\mathrm{J} /(\mathrm{kg} \mathrm{K})$ \\
\hline$d$ & Particle diameter, $\mathrm{m}$ \\
\hline$D$ & Deposition speed at bottom of two-layer PDC, $\mathrm{m} / \mathrm{s}$ \\
\hline$E$ & Entrainment coefficient \\
\hline$F_{\mathrm{N}}$ & Imposed frontal non-dimensional parameter \\
\hline$g$ & Gravitational acceleration, $\mathrm{m} / \mathrm{s}^{2}$ \\
\hline$h$ & Flow thickness (of suspended load), $\mathrm{m}$ \\
\hline$m$ & Empirical exponent \\
\hline$n$ & Mass fraction \\
\hline$p$ & Thermodynamic pressure, $\mathrm{Pa}$ \\
\hline$R$ & Gas constant, J/(kg K) \\
\hline $\operatorname{Re}$ & Reynolds number \\
\hline$R i$ & Richardson number \\
\hline$t$ & Time, s \\
\hline$T$ & Temperature (of suspended load), K \\
\hline$u$ & Velocity component (of suspended load) in $x$ direction, $\mathrm{m} / \mathrm{s}$ \\
\hline$W_{\mathrm{s}}$ & $\begin{array}{l}\text { Settling speed of solid particles at bottom (of suspended load), } \\
\mathrm{m} / \mathrm{s}\end{array}$ \\
\hline$W_{\mathrm{T}}$ & (Mean) terminal velocity of solid particles, $\mathrm{m} / \mathrm{s}$ \\
\hline$x$ & Distance in direction parallel to basal surface, $\mathrm{m}$ \\
\hline$z$ & Height in direction perpendicular to basal surface, $\mathrm{m}$ \\
\hline$\eta$ & Dynamic viscosity, $\mathrm{Pa} \mathrm{s}$ \\
\hline$\theta$ & Slope angle \\
\hline$\rho$ & Mass density (of suspended load), $\mathrm{kg} / \mathrm{m}^{3}$ \\
\hline$\phi$ & Volume fraction \\
\hline \multicolumn{2}{|c|}{ Subscript } \\
\hline $\mathrm{a}$ & Air \\
\hline $\mathrm{b}$ & Bottom of bed load \\
\hline $\mathrm{c}$ & Contact surface between suspended and bed loads \\
\hline $\mathrm{D}$ & Deposit \\
\hline f & Upper surface of suspended load \\
\hline $\mathrm{g}$ & Gas phase (i.e., entrained air and volcanic gas) \\
\hline $\mathrm{H}$ & Bed load (i.e., higher particle concentration region) \\
\hline$i$ & Particle class for experimental data \\
\hline $\mathrm{N}$ & Front (i.e., nose) of current \\
\hline $\mathrm{s}$ & Solid particle \\
\hline $\mathrm{v}$ & Volcanic gas \\
\hline 1 & $\begin{array}{l}\text { Inlet source boundary for PELE experiment (i.e., Profile } 1 \\
\quad(x=0))\end{array}$ \\
\hline * & Suspended load or bed load \\
\hline
\end{tabular}


Supplementary Information The online version contains supplementary material available at https://doi.org/10.1007/ s00445-021-01493-w.

Acknowledgements The manuscript was improved by the comments from Greg A. Valentine, Olivier Roche, and Benjamin J. Andrews. We thank Tomaso Esposti Ongaro for his contribution to defining the benchmark of PDC models.

Funding This work was supported by MEXT KAKENHI Grant Numbers JP17H02949 and JP21K14018 and by MEXT's "Integrated Program for Next Generation Volcano Research and Human Resource Development."

Data availability Not applicable.

Code availability The complete code of the present two-layer PDC model (referred to as "SKS-1D:1.0"), including post-processing scripts (to plot the solution variables and create animations), is available at https://github.com/HiroyukiShimizu/SKS-1D (last access: 3 September 2021).

\section{Declarations}

Conflict of interest The authors declare no competing interests.

Open Access This article is licensed under a Creative Commons Attribution 4.0 International License, which permits use, sharing, adaptation, distribution and reproduction in any medium or format, as long as you give appropriate credit to the original author(s) and the source, provide a link to the Creative Commons licence, and indicate if changes were made. The images or other third party material in this article are included in the article's Creative Commons licence, unless indicated otherwise in a credit line to the material. If material is not included in the article's Creative Commons licence and your intended use is not permitted by statutory regulation or exceeds the permitted use, you will need to obtain permission directly from the copyright holder. To view a copy of this licence, visit http://creativecommons.org/licenses/by/4.0/.

\section{References}

Andrews BJ, Manga M (2011) Effects of topography on pyroclastic density current runout and formation of coignimbrites. Geology 39:1099-1102. https://doi.org/10.1130/G32226.1

Andrews BJ, Manga M (2012) Experimental study of turbulence, sedimentation, and coignimbrite mass partitioning in dilute pyroclastic density currents. J Volcanol Geotherm Res 225-226:30-44. https://doi.org/10.1016/j.jvolgeores.2012.02.011

Benage MC, Dufek J, Mothes PA (2016) Quantifying entrainment in pyroclastic density currents from the Tungurahua eruption, Ecuador: integrating field proxies with numerical simulations. Geophys Res Lett 43:6932-6941. https://doi.org/10.1002/2016GL069527

Benjamin TB (1968) Gravity currents and related phenomena. J Fluid Mech 31:209-248. https://doi.org/10.1017/S0022112068000133

Bonnecaze RT, Huppert HE, Lister JR (1993) Particle-driven gravity currents. J Fluid Mech 250:339-369. https://doi.org/10.1017/ S002211209300148X

Branney MJ, Kokelaar P (2002) Pyroclastic density currents and the sedimentation of ignimbrites. Geol Soc Memoir 27

Breard ECP, Lube G, Jones JR, Dufek J, Cronin SJ, Valentine GA, Moebis A (2016) Coupling of turbulent and non-turbulent flow regimes within pyroclastic density currents. Nat Geosci 9:767771. https://doi.org/10.1038/ngeo2794

Breard ECP, Dufek J, Lube G (2018) Enhanced mobility in concentrated pyroclastic density currents: an examination of a self-fluidization mechanism. Geophys Res Lett 45:654-664. https://doi. org/10.1002/2017GL075759

Brosch E, Lube G (2020) Spatiotemporal sediment transport and deposition processes in experimental dilute pyroclastic density currents. J Volcanol Geotherm Res 401:106946. https://doi.org/10. 1016/j.jvolgeores.2020.106946

Burgisser A, Bergantz GW (2002) Reconciling pyroclastic flow and surge: the multiphase physics of pyroclastic density currents. Earth Planet Sci Lett 202(2):405-418. https://doi.org/10.1016/ S0012-821X(02)00789-6

Bursik MI, Woods AW (1996) The dynamics and thermodynamics of large ash flows. Bull Volcanol 58:175-193. https://doi.org/10. 1007/s004450050134

Cas RAF, Wright JV (1987) Volcanic successions, modern and ancient. Allen and Unwin, London

Choux CM, Druitt TH (2002) Analogue study of particle segregation in pyroclastic density currents, with implications for the emplacement mechanisms of large ignimbrite. Sedimentology 49:907928. https://doi.org/10.1046/j.1365-3091.2002.00481.x

Doyle EE, Hogg AJ, Mader HM, Sparks RSJ (2008) Modeling dense pyroclastic basal flows from collapsing columns. Geophys Res Lett 35:L04305. https://doi.org/10.1029/2007GL032585

Druitt TH, Avard G, Bruni G, Lettieri P, Maez F (2007) Gas retention in fine-grained pyroclastic flow materials at high temperatures. Bull Volcanol 69(8):881-901. https://doi.org/10.1007/ s00445-007-0116-7

Dufek J, Bergantz GW (2007) Dynamics and deposits generated by the Kos Plateau Tuff eruption: controls of basal particle loss on pyroclastic flow transport. Geochem Geophys Geosyst 8(12):Q12007. https://doi.org/10.1029/2007GC001741

Esposti Ongaro T, Neri A, Menconi G, de'Michieli Vitturi M, Marianelli P, Cavazzoni C, Erbacci G, Baxter PJ (2008) Transient 3D numerical simulations of column collapse and pyroclastic density current scenarios at Vesuvius. J Volcanol Geotherm Res 178(3):378-396. https://doi.org/10.1016/j.jvolgeores.2008.06.036

Esposti Ongaro T, Cerminara M, Charbonnier SJ, Lube G, Valentine GA (2020) A framework for validation and benchmarking of pyroclastic current models. Bull Volcanol 82:51. https://doi.org/10. 1007/s00445-020-01388-2

Fisher RV, Schmincke H-U (1984) Pyroclastic rocks. Springer, Berlin

Girolami L, Druitt TH, Roche O, Khrabrykh Z (2008) Propagation and hindered settling of laboratory ash flows. J Geophys Res 113:B02202. https://doi.org/10.1029/2007JB005074

Girolami L, Roche O, Druitt TH, Corpetti T (2010) Particle velocity fields and depositional processes in laboratory ash flows, with implications for the sedimentation of dense pyroclastic flows. Bull Volcanol 72(6):747-759. https://doi.org/10.1007/ s00445-010-0356-9

Hager WH (1988) Abflussformeln für turbulente Strömungen. Wasserwirtschaft 78:79-84

Hogg AJ, Pritchard D (2004) The effects of hydraulic resistance on dam-break and other shallow inertial flows. J Fluid Mech 501:179-212. https://doi.org/10.1017/S0022112003007468

Kelfoun K (2017) A two-layer depth-averaged model for both the dilute and the concentrated parts of pyroclastic currents. J Geophys Res 122:4293-4311. https://doi.org/10.1002/2017JB014013

Khan AR, Richardson JF (1989) Fluid-particle interactions and flow characteristics of fluidized beds and settling suspensions of spherical particles. Chem Eng Commun 78:111-130. https://doi.org/10. 1080/00986448908940189

Kunii D, Levenspiel O (1969) Fluidization engineering. John Wiley, New York 
Lube G, Breard ECP, Cronin SJ, Jones J (2015) Synthesizing largescale pyroclastic flows: experimental design, scaling, and first results from PELE. J Geophys Res 120:1487-1502. https://doi. org/10.1002/2014JB011666

Lube G, Breard ECP, Jones J, Fullard L, Dufek J, Cronin SJ, Wang $\mathrm{T}$ (2019) Generation of air lubrication within pyroclastic density currents. Nat Geosci 12:381-386. https://doi.org/10.1038/ s41561-019-0338-2

Lube G, Breard ECP, Esposti-Ongaro T, Dufek J, Brand B (2020) Multiphase flow behaviour and hazard prediction of pyroclastic density currents. Nat Rev Earth Environ 1:348-365. https://doi. org/10.1038/s43017-020-0064-8

Marble FE (1970) Dynamics of dusty gases. Annu Rev Fluid Mech 2:397-446. https://doi.org/10.1146/annurev.fl.02.010170.002145

Parker G, Garcia M, Fukushima Y, Yu W (1987) Experiments on turbidity currents over an erodible bed. J Hydraul Res 25:123-147. https://doi.org/10.1080/00221688709499292

Richardson JF, Zaki WN (1954) Sedimentation and fluidization: part I. Trans Inst Chem Eng 32:35-52

Roche O, Montserrat S, Niño Y, Tamburrino A (2008) Experimental observations of water-like behavior of initially fluidized, dam break granular flows and their relevance for the propagation of ash-rich pyroclastic flows. J Geophys Res 113:B12203. https:// doi.org/10.1029/2008JB005664

Roche O, Buesch D, Valentine GA (2016) Slow-moving and far-travelled dense pyroclastic flows during the Peach Spring super-eruption. Nat Commun 7:10890. https://doi.org/10.1038/ncomms 10890

Roche O, Azzaoui N, Guillin A (2021) Discharge rate of explosive volcanic eruption controls runout distance of pyroclastic density currents. Earth Planet Sci Lett 568:117017. https://doi.org/10. 1016/j.eps1.2021.117017
Shimizu HA, Koyaguchi T, Suzuki YJ (2017) A numerical shallowwater model for gravity currents for a wide range of density differences. Prog Earth Planet Sci 4(1):8. https://doi.org/10.1186/ s40645-017-0120-2

Shimizu HA, Koyaguchi T, Suzuki YJ (2019) The run-out distance of large-scale pyroclastic density currents: a two-layer depth-averaged model. J Volcanol Geotherm Res 381:168-184. https://doi. org/10.1016/j.jvolgeores.2019.03.013

Sparks RSJ, Bonnecaze RT, Huppert HE, Lister JR, Hallworth MA, Mader H, Phillips J (1993) Sediment-laden gravity currents with reversing buoyancy. Earth Planet Sci Lett 114:243-257. https:// doi.org/10.1016/0012-821X(93)90028-8

Sulpizio R, Dellino P, Doronzo DM, Sarocchi D (2014) Pyroclastic density currents: state of the art and perspectives. J Volcanol Geotherm Res 283:36-65. https://doi.org/10.1016/j.jvolgeores. 2014.06.014

Ungarish M (2009) An introduction to gravity currents and intrusions. CRC Press, Boca Raton

Valentine GA (1987) Stratified flow in pyroclastic surges. Bull Volcanol 49(4):616-630. https://doi.org/10.1007/BF01079967

Valentine GA (2019) Preface to the topical collection - pyroclastic current models: benchmarking and validation. Bull Volcanol 81:69. https://doi.org/10.1007/s00445-019-1328-3

Valentine GA (2020) Initiation of dilute and concentrated pyroclastic currents from collapsing mixtures and origin of their proximal deposits. Bull Volcanol 82:20. https://doi.org/10.1007/ s00445-020-1366-x

Weit A, Roche O, Dubois T, Manga M (2018) Experimental measurement of the solid particle concentration in geophysical turbulent gas-particle mixtures. J Geophys Res 123:3747-3761. https://doi. org/10.1029/2018JB015530 